BRE 21063

\title{
Enduring enhancoment in frontal cortex dopamine utilization in an animal model of amphetamine psychosis
}

\author{
TERRY E. ROBINSON, JILL B. BECKER, C. J. MOORE, E. CASTAÑEDA and G. MITTLEMAN \\ Psychology Department and Neuroscience Laboratory Building, The University of Michigan, Ann Arbor, MI 48104-1687(U.S.A.)
}

(Accepted May 7th, 1983)

Key words: amphetamine - frontal cortex — dopamine - sensitization — amphetamine psychosis - striatum - stress

\begin{abstract}
It is reported that in rats the repeated intermittent administration of amphetamine produces a long-lasting enhancement in medial frontal cortex dopamine utilization. This change in mesocortical dopamine activity may be involved in the behavioral sensitization produced by psychomotor stimulant drugs, and some of the cognitive abnormalities (e.g. amphetamine psychosis) associated with stimulant drug abuse in humans.
\end{abstract}

People who are repeatedly exposed to psychomotor stimulant drugs, such as amphetamine (AMP) or cocaine, sometimes develop cognitive and behavioral abnormalities that are similar to those associated with paranoid schizophrenia ${ }^{10,14,16,24}$. Although this AMP psychosis dissipates upon withdrawal from the drug, former AMP addicts are hypersensitive to the psychotomimetic effects of AMP even after years of abstinence ${ }^{30}$. This suggests that AMP produces a very long-lasting change in some neural system(s) involved in the psychotomimetic effects of stimulants.

The repeated intermittent administration of AMP to non-human animals also produces progressive and enduring changes in behavior, a phenomenon known as behavioral sensitization 12.17 .19 .32 . It is thought that behavioral sensitization represents an animal model of AMP psychosis $24.25,31: 33$, and therefore there have been many attempts to identify an enduring change in the brains of non-human animals previously exposed to AMP2.23.25.33. Most of these latter studies have concentrated on the mesostriatal dopamine (DA) system, largely because AMP causes DA release, and mesostriatal DA neurons are known to be important in mediating some of the behavioral effects of AMP. However, despite these efforts, the neural basis of behavioral sensitization is not well understood 23.33 .
In the experiments reported here we examined the long-term effects of repeated intermittent injections of AMP on frontal cortex DA activity for two major reasons. One, it seemed possible that a treatment that causes cognitive deficits would involve cortical dysfunction of some kind. Second, it has been suggested that behavioral sensitization is not unique to the psychopharmacology of stimulants, but can also be produced by stress ${ }^{3,4,22}$. One well-established effect of footshock stress is a relatively selective enhancement in mesocortical DA utilization $6,18,26,35$. Therefore, we hypothesized that if AMP produces its enduring effects on brain and behavior by its action as a stressor, it may also produce an enduring enhancement in mesocortical DA utilization.

The first experiment to test this hypothesis was conducted in ovariectomized (OVX) female rats. Female rats were used because: (1) they show much more robust behavioral sensitization than males ${ }^{27,29}$; and (2) OVX females are likely to show less variation in dopaminergic activity than intact cycling females 7.8 . At least 3 weeks after OVX the animals were assigned to one of 3 groups. Animals in two of these groups received 7 daily i.p. injections of either $3.0 \mathrm{mg} / \mathrm{kg}$ D-AMP sulfate or $0.9 \%$ saline. Eight days after the last injection of AMP or saline, all of these animals received an i.p. injection of $200 \mathrm{mg} / \mathrm{kg}$ of $\alpha$ -

Correspondence: T. E. Robinson, Neuroscience Laboratory Building, 1103 E. Huron St. Ann Arbor, MI 48104-1687. U.S.A. 
methyl-D,L-p-tyrosine methyl ester hydrochloride (MPT) in saline to inhibit DA synthesis ${ }^{34}$. Ten min later, half of the AMP- $(n=10)$ and half of the saline$(\mathrm{n}=9)$ pretreated rats were placed in test chambers with a wire grid floor, where they received $20 \mathrm{~min}$ of mild footshock (1.3 mA, 0.5-s duration, every $15 \mathrm{~s})$. The other half were left undisturbed in their home cages. Exactly $30 \mathrm{~min}$ after the injection of MPT each rat was decapitated and the entire medial frontal cortex (anterior to the genu of the corpus callosum), the head and body of the caudate nucleus and the nucleus accumbens were dissected freehand in ice-cold saline. These brain regions were also obtained from animals $(n=9)$ that did not receive MPT or any other experimental treatment. The tissue was assayed for DA by HPLC with electrochemical detection ${ }^{29}$, and the decline in DA following MPT was used as an index of DA utilization 5.9 .35 .

As expected from previous reports $18.26 .35,20 \mathrm{~min}$ of footshock stress significantly elevated frontal cortex DA utilization in saline-pretreated control animals (Fig. 1A). However, of more interest was the effect of AMP pretreatment on cortical DA utilization. Previous exposure to AMP produced an enduring enhancement in mesocortical DA utilization in the absence of footshock stress, such that the addition of footshock stress did not further enhance frontal cortex DA utilization in AMP-pretreated animals (Fig. 1A). This effect was regionally specific, as there was no influence of AMP sensitization or footshock stress on the rate of striatal or nucleus accumbens DA utilization (Fig. 1A).

In a second experiment the effects of AMP sensitization on mesocortical DA utilization were replicated, modifying some procedures. OVX rats were prepared as described above, and then received an i.p. injection of either $3.0 \mathrm{mg} / \mathrm{kg}$ AMP $(\mathrm{n}=12)$ or saline $(n=6)$ every $3-4$ days for a total of 9 injections. An additional 14 animals were left undisturbed (nonhandled) during this time. The dose of AMP and injection regimen used in both experiments 1 and 2 were chosen because they are known to produce robust behavioral sensitization (e.g. refs. 23, 27, 33). Ten days after the last injection, all the AMP and saline pretreated rats and 6 of the non-handled rats received an i.p. injection of $200 \mathrm{mg} / \mathrm{kg}$ of MPT and were then left undisturbed in their home cage for 30 min. These animals, and the remaining 8 non-han- dled animals (which did not receive MPT), were then decapitated and the medial frontal cortex. striatum and nucleus accumbens dissected in ice-cold saline.

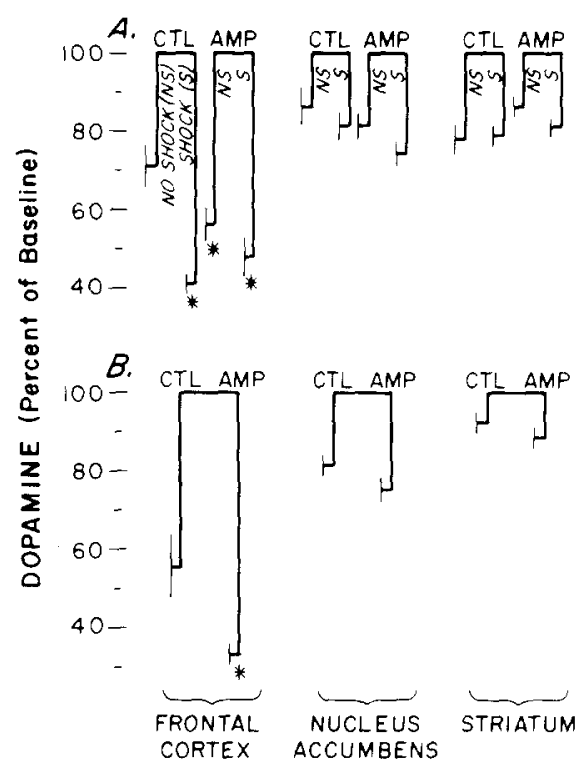

Fig. 1. The effects of exposure to repeated intermittent injections of amphetamine (AMP) on forebrain dopamine (DA) utilization. The heavy vertical lines represent the mean ( \pm S.E.M.) tissue levels of DA 30 min after an i.p. injection of $\alpha$-methyl-ptyrosine (MPT), expressed as a percent of tissue levels in rats that did not receive MPT, or any other experimental treatment (baseline). Note: the lower the number (and longer the line) the greater the rate of DA utilization. $\mathrm{A}$ : in the first experiment, animals were pretreated with saline (CTL) or AMP for 7 days, and then 8 days later received footshock stress (S), or no footshock stress (NS) 20 min before they were decapitated. For frontal cortex there was a significant main effect of stress (twoway analysis of variance: $F=15.7 . P<0.001)$, and a significant stress by pretreatment condition interaction $(F=5.4 . P=$ $0.02)$. The asterisks indicate groups that differed from saline pretreated animals that were not shocked (CTL-NS; planned $t$ tests, $P<0.03)$. In addition. DA utilization in AMP pretreated animals that were not shocked (AMP-NS) did not differ from that in AMP pretreated animals that were shocked (AMP-S). but was less than in saline pretreated animals that were shocked (CTL-S: $P=0.02$ ). There was no significant effect of pretreatment condition or footshock stress on DA utilization in the nucleus accumbens or striatum (two-way analyses of variance non-significant). B: in Experiment 2 animals were either left undisturbed, or pretreated with saline or AMP every 3-4 days for a total of 9 injections. Following MPT there were no differences in DA levels between saline pretreated animals and those left undisturbed, and therefore these groups were pooled to form one control group (CTL). A planned $t$-test showed that, as predicted. DA utilization in the frontal cortex of AMP pretreated rats was greater than in CTL animals $(t=2.3, P=$ 0.015 . one-tailed test). There was no significant effect of pretreatment condition on DA utilization in the nucleus accumbens or striatum. Regional differences in the rate of DA utilization (cortex highest) reported previously are also evident (e.g. ref. 5). 
The dissection procedure differed from the first experiment in that brain slices were obtained using a cutting block described by Heffner et al. ${ }^{15}$. The dissection was as described by Heffner et al. ${ }^{15}$ except: (1) only the anteromedial frontal cortex anterior to the genu of the corpus callosum was removed; and (2) the nucleus accumbens was removed using a micropunch.

Fig. 1B shows that again, frontal cortex DA utilization was significantly enhanced in animals that had been exposed to AMP 10 days earlier, relative to saline-treated controls $(P=0.015)$. As in the first experiment, there was no detectable effect of AMP sensitization on DA utilization in the striatum or nucleus accumbens with this method. Frontal cortex DA levels in AMP pretreated rats were 23.4 and $39.5 \%$ lower than those in saline-pretreated rats in Experiments 1 and 2, respectively. The larger effect in Expt. 2 may be because: (1) these animals received 9 (vs 7) injections of AMP; and/or (2) AMP injections spaced more than 1 day apart (as in Expt. 2) produce more robust sensitization than injections given closer together in time 2.21 .27 .

Although changes in striatal DA utilization were not observed with the methods used here it is still possible that AMP sensitization alters mesostriatal or mesolimbic DA activity. For example, it has been shown that AMP-stimulated endogenous DA release from striatal tissue in vitro is enhanced for at least a month following exposure to AMP in vivo (refs. 28, 29, also see ref. 20). In these latter studies AMP sensitization did not influence the basal levels of DA release or turnover, but enhanced the response to a subsequent AMP 'challenge'20,28,29. This raises the

1 Anisman, H., Vulnerability to depression: contribution of stress. In R. M. Post and J. C. Ballenger (Eds.), Neurobiology of Mood Disorders, Vol. 1, Frontiers of Clinical Neuroscience, Williams and Wilkins, Baltimore, MD 1984, pp. 407-431.

2 Antelman, S. M. and Chiodo, L. A., Dopamine autoreceptor subsensitivity: a mechanism common to the treatment of depression and the induction of amphetamine psychosis, Biol. Psychiat., 16 (1981) 717-727.

3 Antelman, S. M. and Chiodo, L. A., Amphetamine as a stressor. In I. Creese (Ed.), Stimulants: Neurochemical, Behavioral, and Clinical Perspectives, Raven Press, New York, 1983, pp. 269-299. possibility that the increase in mesocortical DA utilization observed here does not represent a change in the basal rate of DA utilization. Perhaps prior exposure to AMP resulted in enhanced sensitivity to subsequent stress, and the elevated rate of mesocortical DA utilization was in fact an exaggerated response to the stress of the MPT injection. Changes in striatal activity may not have been observed because: (1) the mesostriatal system is less responsive to stress than the mesocortical DA system $5,6,26,35$; or (2) the striatal response to stress is a more rapid and transient event than the cortical response ${ }^{3.4}$.

In conclusion, these experiments show for the first time that the repeated intermittent exposure to AMP produces an enduring (at least 10 days) enhancement in medial frontal cortex DA utilization (cf. ref. 13). Whether the exposure to repeated intermittent stress produces comparable enduring changes in mesocortical DA activity remains to be determined. Nevertheless, we are compelled to speculate that enhanced mesocortical DA activity may be involved in the behavioral changes associated with AMP sensitization in non-human animals, and the cognitive abnormalities associated with both stimulant drug abuse and stress-precipitated psychopathologies thought to involve brain catecholamine dysfunction in humans $1.4,11.24 .25 .33$

This research was supported by NIMH Grant 37277. T.E.R. is supported by Research Career Development Award NS 00844. We thank C. de Sibour, K. Einhaus, P. Jefferson, M. Miller, T. Smith, S. Westgate and R. Wilcox for their help with the assays.

4 Antelman, S. M. and Chiodo, L. A., Stress: its effect on interactions among biogenic amines and the role in the induction and treatment of disease. In L. L. Iversen, S. D. Iversen and S. H. Snyder (Eds.), Handbook of Psychopharmacology, Vol. 18, Plenum, New York, 1984, pp . 279-341.

5 Bannon, M. J., Bunney, E. B. and Roth, R. H., Mesocortical dopamine neurons: rapid transmitter turnover compared to other brain catecholamine systems, Brain Research, 218 (1981) 376-382.

6 Bannon, M. J. and Roth, R. H., Pharmacology of mesocortical dopamine neurons. Pharmacol. Rev., 35 (1983) $53-68$.

7 Becker, J. B. and Ramirez, V. D., Sex differences in the 
amphetamine-stimulated release of catecholamines from rat striatal tissue in vitro. Brain Research, 204 (1981) $361-372$.

8 Becker, J. B., Robinson, T. E. and Lorenz, K. A., Sex differences and estrous cycle variations in amphetamine-elicited rotational behavior, Eur. J. Pharmacol., 80 (1982) $65-72$.

9 Brodic, B. B., Costa, E., Dlabac, A., Neff, N. H, and Smookler, H. H.. Application of steady state kinetics to the estimation of synthesis rate and turnover time of tissue catecholamines. J. Pharmacol. Exp. Ther., 154 (1966) 493-498.

10 Connell. P. H., Amphetamine Psychosis, Chapman and Hill, London, 1958.

11 Dohrenwend. B. P. and Egri, G., Recent stressful life events and episodes of schizophrenia, Schizophrenia Bull., 7 (1981) 12-23.

12 Echols, S. D., Circling of mice bearing unilateral striatal lesions: development of increased response to D-amphetamine, Life Sci., 21 (1977) 563-568.

13 Eichler, A. J. and Antelman, S. M., Sensitization to amphetamine and stress may involve nucleus accumbens and medial frontal cortex, Brain Research, 176 (1979) 412-416.

14 Ellinwood, E. H., Sudilovsky, A. and Nelson, L. M., Evolving behavior in the clinical and experimental (model) psychosis. Am. J. Psychiatry, 130 (1973) 1088-1092.

15 Heffner. T. G.. Hartman. J. A. and Seiden, L. S., A rapid method for the regional dissection of the rat brain, Pharmacol. Biochem. Behav., 13 (1980) 453-456.

16 Janowsky. D. S. and Risch, C., Amphetamine psychosis and psychotic symptoms, Psychopharmacology, 65 (1979) $73-77$.

17 Klawans, H. L. and Margotin, D. J., Amphetamine-induced dopaminergic hypersensitivity in guinea pigs, Arch. Gen. Psychiatry, 32 (1975) 725-732.

18 Lavielle, S., Tassin, J. P.. Thierry, A. M., Blanc, G., Herve, D., Barthelemy, C. and Glowinski, J., Blockade by benzodiazepines of the selective high increase in dopamine turnover induced by stress in mesocortical dopaminergic neurons of the rat, Brain Research, 168 (1978) 585-594.

19 Magos. L., Persistence of the effect of amphetamine on stereotyped activity in rats, Eur. J. Pharmacol., 6 (1969) 200-201.

20 Nishikawa, T., Mataga, N., Takashima, M. and Toru, M., Behavioral sensitization and relative hyperresponsiveness of striatal and limbic dopaminergic neurons after repeated methamphetamine treatment, Eur. J. Pharmacol., 88 (1983) 195-203.

21 Post. R. M., Intermittent versus continuous stimulation: effect of time interval on the development of sensitization or tolerance, Life Sci., 26 (1980) 1275-1282.

22 Post, R. M., Cocaine psychosis: a continuum model, Am. J. Psvchiatry. 132 (1975) 225-231.

23 Post, R. M., Central stimulants: clinical and experimental evidence on tolerance and sensitization. In Y. Israel. F. B. Glaser. H. Kalarit, R. E. Pophano, W. Schmidt and R. G.
Smart (Eds.), Research Advances in Alcohol and Drug Problems, Vol. 6, Plenum Press, New York, 1981, pp. $1-65$.

24 Post, R. M. and Contel, N. R., Human and animal studies of cocaine: implications for development of behavioral pathology. In I. Creese (Ed.), Stimulants: Neurochemical, Behavioral, and Clinical Perspectives, Raven Press. New York, 1983, pp. 169-203.

25 Post, R. M., Rubinow, D. R. and Ballenger, J. C. Conditioning, sensitization, and kindling: implications for the course of affective illness. In R. M. Post and J. C. Ballenger (Eds.), Neurobiology of Mood Disorders. Frontiers of Clinical Neuroscience, Williams and Wilkens. Baltimore, MD. 1984, pp. 432-466.

26 Reinhard, J. F., Bannon, M. J. and Roth, R. H., Acceleration by stress of dopamine synthesis and metabolism in prefrontal cortex: antagonism by diazepam, NaunynSchmiedeberg's Arch. Pharmacol., 318 (1982) 374-377.

27 Robinson, T. E., Behavioral sensitization: characterization of enduring changes in rotational behavior produced by intermittent injections of amphetamine in male and female rats, Psychopharmacology, 84 (1984) 466-475.

28 Robinson, T. E. and Becker, J. B., Behavioral sensitization is accompanied by an enhancement in amphetamine-stimulated dopamine release from striatal tissue in vitro, Eur. J. Pharmacol., 85 (1982) 253-254.

29 Robinson, T. E., Becker, J. B. and Presty, S. K.. Longterm facilitation of amphetamine-induced rotational behavior and striatal dopamine release produced by a single exposure to amphetamine: sex differences. Brain Research, 253 (1982) 231-241.

30 Sato, M., Chen, C.-C., Akiyama, K. and Otsuki, S., Acute exacerbation of paranoid psychotic state after long-term abstinence in patients with previous methamphetamine psychosis, Biol. Psychiatry, 18 (1983) 429-440.

31 Segal, D. S. and Janowsky, D. S., Psychostimulant-induced behavioral effects: possible models of schizophrenia. In $\mathrm{M}$. A. Lipton, A. DiMascio, and K. F. Killam (Eds.), Psychopharmacology: A Generation of Progress, Raven Press, New York, 1978, pp. 1113-1123.

32 Segal, D. S. and Mandell, A. J, , Long-term administration of amphetamine: progressive augmentation of motor activity and stereotypy, Pharmacol. Biochem. Behav., 2 (1974) 249-255.

33 Segal, D. S. and Schuckit, M. A., Animal models of stimulant-induced psychosis. In I. Creese (Ed.), Stimulants: Neurochemical, Behavioral, and Clinical Perspectives, Raven Press, New York, 1983, pp. 131-167.

34 Spector, S., Sjoerdsma, A. and Udenfriend, S., Blockade of endogenous norepinephrine synthesis by $\alpha$-methyl-tyrosine, an inhibitor of tyrosine hydroxylase, J. Pharmacol. Exp. Ther., 147 (1965) 86-95.

35 Thierry, A. M., Tassin, J. P., Blanc, G. and Glowinski, J., Selective activation of the mesocortical DA system by stress, Nature (London), 263 (1976) 242-244. 